\title{
Changes in precipitation extremes over Eastern China simulated by the Beijing Climate Center Climate System Model (BCC_CSM1.0)
}

\author{
Li Zhang*, Min Dong, Tongwen Wu \\ Beijing Climate Center, China Meteorological Administration, Beijing, PR China
}

\begin{abstract}
Performance of the Beijing Climate Center Climate System Model (BCC_CSM1.0) in simulating the regional extreme precipitation change over eastern China east of $105^{\circ} \mathrm{E}$ was evaluated. Daily observed precipitation data for 1956-2009 at 349 rain gauge stations in China were used for comparison. The 20th century simulation forced by observed greenhouse gases, aerosols, solar irradiance and volcanic aerosols shows that (1) BCC_CSM1.0 can reproduce the basic feature of observed climatology of annual total precipitation and extreme precipitation over the 95th percentile, with spatial correlation of 0.77 for both of them. (2) BCC_CSM1.0 is also able to capture the main change patterns of yearly accumulated extreme precipitation above the 95th percentile, although there are some model biases in the spatial extension and strength. Some model biases are also noted: (1) Annual total and extreme precipitation south of Yangtze River are underestimated. (2) Frequency of heavy precipitation $\left(\geq 25.0 \mathrm{~mm} \mathrm{~d}^{-1}\right)$ over eastern China is underestimated, but the frequency of light rain ( 0.1 to $9.9 \mathrm{~mm} \mathrm{~d}^{-1}$ ) is overestimated. (3) Simulated long-term trends of annual extreme precipitation amount and frequency in the last $50 \mathrm{yr}$ are the opposite of the observations in North and South China.
\end{abstract}

KEY WORDS: Extreme precipitation $\cdot$ Eastern China $\cdot$ BCC_CSM1.0 $\cdot$ Evaluation

\section{INTRODUCTION}

Under the background of global warming, frequencies and intensities of extreme climate events may either increase or decrease, with obvious regional differences (IPCC 2007). More and more attention has been paid to the variations and trends in extreme precipitation (Easterling et al. 2000, Karl \& Easterling 1999). Both frequencies and intensities of extreme precipitation over mid- and high-latitude land regions of the North Hemisphere have increased in recent decades (Alexander et al. 2006) and might be a response to the anthropogenic global warming (e.g. IPCC 2007, Zhang et al. 2007).

It seems that flood disasters in China, especially in the eastern part, occurred more frequently in the late 1990s than during other periods, which brought enormous economic losses (Wu 2002). In the last decade, there have been many studies focusing on extreme precipitation events over China (Zhai et al. 1999a,b, 2005, Yan \& Yang 2000, Zhai \& Pan 2003, Qian et al. 2007, You et al. 2010, Dong et al. 2011, Gemmer et al. 2011). Extreme precipitation exhibits increasing trends over northwest and southwest China, the Yangtze River Basin, and southeastern and southern coast regions of China (Zhai et al. 2005, Yang et al. 2008, You et al. 2010). There are decreasing trends over Sichuan Basin (You et al. 2010) and northern China (Zhai et al. 2005, Yang et al. 2008, You et al. 2010), such as the mid-lower reaches of the Yellow River Basin and the Huaihe River Basin (Dong et al. 2011). Regional analysis 
shows that abrupt changes occurred in Northeast and North China (Yang et al. 2008). At the same time, there were no significant trends for extreme maximum daily precipitation in most of the 60 stations analyzed during 1951-1997 over China (Yan \& Yang 2000). Monthly data analysis shows that the positive and negative trends of precipitation are significant in all months except December, and nearly $90 \%$ of the driest October months can be explained by wind directions typical of the East Asian winter monsoon (Gemmer et al. 2011). The frequencies of extreme precipitation events in different seasons on a regional scale exhibit significant interannual and interdecadal variabilities (Chen et al. 2009, Ning \& Qian 2009). The latent heat flux over the South China Sea and the sensible heat flux over the Indochina Peninsula influence extreme precipitation in different calendar months. These effects are achieved by the interdecadal increase of the strengthening convection over South China through the South China Sea summer monsoon (Ning \& Qian 2009). The annual and interannual trends of the $500 \mathrm{hPa}$ geopotential height and $850 \mathrm{hPa}$ horizontal winds over the Eurasian continent affect Chinese summer extreme wet and dry events (Weng et al. 2004).

Rapid advances in climate modeling improved the estimation of climate change during the past decades. Although several climate models reasonably capture the main characteristics of the spatial distribution and linear trends of precipitation extremes (Jiang et al. 2009), the coupled climate system models often lack skill for simulating extreme precipitation (Sun et al. 2006, Kiktev et al. 2003). The projections of future changes in extreme events, however, still depend on the climate model. Increases in extreme precipitation greater than the mean under increased greenhouse gases have been reported in many climate models both on global and regional scales (Pall et al. 2007). The projection of extreme precipitation over China has also been analyzed based on the output from the Fourth Assessment Report (AR4) of the Intergovernmental Panel on Climate Change (IPCC) (Jiang et al. 2009).

Beijing Climate Center Climate System Model version 1.0 (BCC-CSM1.0) is a fully-coupled climate model developed by the Beijing Climate Center. Several studies (e.g. Chen 2008, Zhang et al. in press) show that BCC_CSM1.0 can capture the basic climate feature of summer atmospheric circulation and precipitation over East Asia. This study will focus on the model performance in simulating extreme precipitation in the last $50 \mathrm{yr}$.

\section{MODEL, DATA AND METHODS}

\subsection{Model and experiment design}

The BCC-CSM1.0 is a global fully-coupled climate model. It is originated from the Community Climate System Model version 2 (CCSM2; Kiehl \& Gent 2004). The main differences between the BCC-CSM1.0 and CCSM2 are their atmospheric and land surface model components. For the atmosphere, the BCCCSM1.0 uses an atmospheric general circulation model BCC-AGCM2.0.1 developed by the BCC (for details see Wu et al. 2008, 2010). It is a spectral model with horizontal T42 truncation $\left(\sim 2.8125^{\circ}\right.$ horizontal resolution) and 26 layers in the vertical direction. It performs well in simulating the basic climate of precipitation, temperature, thermal structure and atmospheric circulation (Wu et al. 2010), intraseasonal oscillations of zonal wind and precipitation (Dong et al. 2009), and the Asian-Australian Monsoon (Wang et al. 2009). The land surface model component in BCC-CSM1.0 is the Community Land Model (CLM) v. 3, which displaced CLM v. 2 used in CCSM2 (Dickinson et al. 2006). The ocean model (Parallel Ocean Program [POP]) and ice model (Community Sea Ice Model version 4 [CSIM4]) are the same as those in CCSM2. The ocean model POP has 40 vertical levels and tripolar grids in the horizontal. The longitudinal resolution is $\sim 1^{\circ}$ and the latitudinal resolution is variable with finer resolution $\left(\sim 0.3^{\circ}\right)$ near the equator.

In order to evaluate the capability of BCC_CSM1.0 for historical climate simulation, the 20th century historical experiment $(20 \mathrm{C} 3 \mathrm{M})$ is carried out. In the simulation of 20C3M, BCC-CSM1.0 was forced by observed greenhouse gases, aerosols, solar irradiance, and volcanic aerosols used in IPCC AR4 experiments. A pre-industrial control experiment was carried out first with the external forcing fixed to the values of 1870, initialized from a present-day control run of $500 \mathrm{yr}$. With $\sim 100 \mathrm{yr}$ of spin-up, the global mean sea surface temperature (SST) and sea ice fraction became stable, then the $20 \mathrm{C} 3 \mathrm{M}$ run was branched from the pre-industrial control run with year-to-year changed external forcing from 1870 to 1999, and then continuously run with the corresponding external forcing according to SRESB1 (IPCC 2000) until 2010.

\subsection{Data}

The observed precipitation data from 1956 to 2009 at 349 rain gauge stations over the eastern part of China east of $105^{\circ} \mathrm{E}$ (Fig. 1) are used in this study. 
They were selected from a new dataset with a higher spatial density, and the quality control has been done by the National Meteorological Information Center of China Meteorological Administration (CMA) using climatic extreme value check, extreme value check, and internal consistency examination. This dataset has not been used in extreme precipitation research before. In order for inter-comparison, the model data are linearly interpolated into $0.5 \times 0.5^{\circ}$ gridded points, and the station observations are interpolated to the same gridded points using 'oacres' function in the meteorological software Grads.

The National Center for Environmental Prediction/ National Center for Atmospheric Research (NCEP/ NCAR) reanalysis dataset v. 1 (Kalnay et al. 1996) is used to analyze the atmospheric circulation background over East Asia. The horizontal resolution of the data is $2.5 \times 2.5^{\circ}$. The monthly precipitation data from Climate Prediction Center (CPC) Merged Analysis of Precipitation (CMAP) dataset (Xie \& Arkin 1997) is also used in this study. For inter-comparison, the model output data are linearly interpolated into the same grid points as the reanalysis data.

\subsection{Extreme precipitation indices and analysis methods}

Daily precipitation intensity was classified into 5 categories: light rain $\left(0.1-9.9 \mathrm{~mm} \mathrm{~d}^{-1}\right)$, moderate rain (10.0-24.9 $\mathrm{mm} \mathrm{d}^{-1}$ ), heavy rain (25.0-49.9 $\mathrm{mm} \mathrm{d}^{-1}$ ), rainstorm (50.0-99.9 $\mathrm{mm} \mathrm{d}^{-1}$ ), and heavy rainstorm $\left(\geq 100.0 \mathrm{~mm} \mathrm{~d}^{-1}\right.$ ). To consider large-scale differences

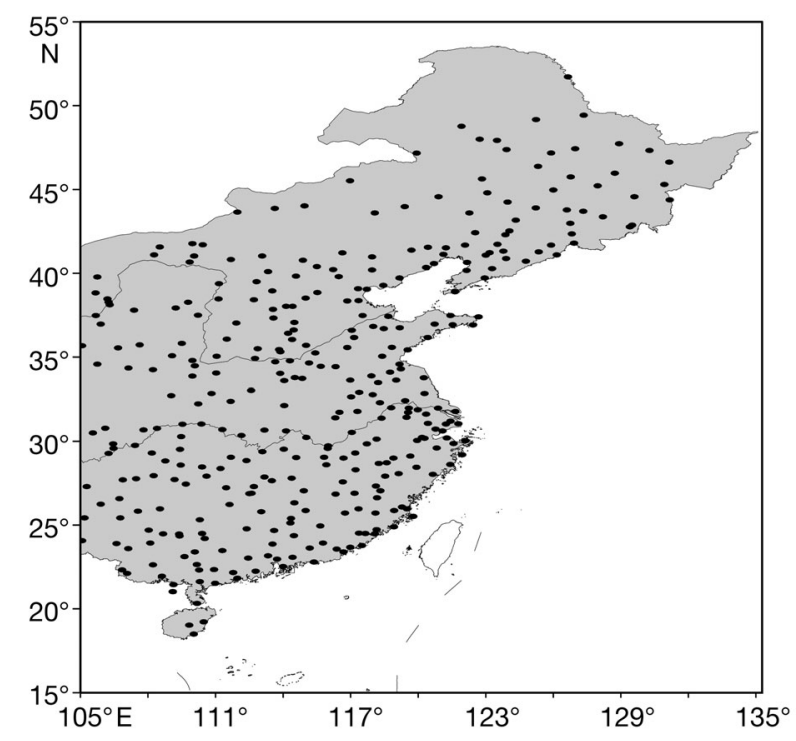

Fig. 1. Distribution of stations in precipitation, we used percentiles to analyse the precipitation extremes.

The thresholds of extreme precipitation are estimated on the basis of percentiles. First, the time series of the 95th percentile of daily precipitation amounts for all rainy days (precipitation $\geq 1.0 \mathrm{~mm} \mathrm{~d}^{-1}$ ) of each year from 1971 to 2000 are calculated. Then the $30 \mathrm{yr}$ (1971-2000) mean is regarded as the extreme precipitation threshold. The thresholds for separate stations are different. The nonparametric method is used to determine the threshold (for details refer to Bonsal et al. 2001). As for each station, the amount of daily precipitation $\left(\geq 1.0 \mathrm{~mm} \mathrm{~d}^{-1}\right)$ was ranked in ascending order: $X_{1}, X_{2}, \ldots, X_{\mathrm{N}}$. The probability $P_{m}$ for each rank $m(m=1,2, \ldots, N$; where $N$ is the length of the record) can be estimated by:

$$
P_{m}=(m-0.31) /(N+0.38)
$$

Here, $P_{m}$ is an ascending series. Then the precipitation amount at the 95th percentile (hereafter R95) can be linearly interpolated from the $P_{m}$ series. This method to estimate the percentiles is simple and avoids any other assumptions of the underlying distributions (Bonsal et al. 2001).

Then, the number of days with rainfall above R95 (R95p), the total precipitation above R95 (R95pTOT), and the intensity index of the extreme precipitation (R95pI) defined as: R95pI = R95pTOT / R95p, can be calculated. The daily precipitation intensity index (SDII) is also used in this work. It is defined as the rate of total precipitation (PRCPTOT) over total precipitation days above $1.0 \mathrm{~mm} \mathrm{~d}^{-1}$ in a year.

The non-parametric Mann-Kendall method (M-K method) is utilized to test the trend of extreme precipitation (Mann 1945, Kendall 1948, 1975). It has been widely used to evaluate statistically significant trends in hydrological and climatological time series (e.g. Xu et al. 2004, Zheng et al. 2007). As for the given time series of $x_{i}(i=1, n)$, its statistic variable $Z_{\mathrm{c}}$ is introduced as:

$$
Z_{\text {c }}= \begin{cases}\frac{S-1}{\sqrt{\operatorname{var}(S)}}, & S>0 \\ 0 & , S=0 \\ \frac{S+1}{\sqrt{\operatorname{var}(S)}}, & S<0\end{cases}
$$

in which:

$$
\begin{gathered}
S=\sum_{i=1}^{n-1} \sum_{k=i+1}^{n} \operatorname{sgn}\left(x_{k}-x_{i}\right) \\
\operatorname{var}(s)=\left[n(n-1)(2 n+5)-\sum_{t=1}^{n} t(t-1)(2 t+5)\right] / 18
\end{gathered}
$$




$$
\operatorname{sgn}\left(x_{k}-x_{i}\right)= \begin{cases}+1, & x_{k}>x_{i} \\ 0, & x_{k}=x_{i} \\ -1, & x_{k}<x_{i}\end{cases}
$$

$Z_{\mathrm{c}}>0$ indicates the increase trend and $Z_{\mathrm{c}}<0$ the decrease trend, respectively. The magnitude of the trend $(\beta)$ is expressed as:

$$
\beta=\operatorname{Median}\left(\frac{x_{i}-x_{j}}{i-j}\right), 1<j<i<n
$$

where Median () is the value in the median location of a series. A positive value of $\beta$ indicates an increase or upward trend; a negative value of $\beta$ indicates a decrease or downward trend.

Empirical Orthogonal Function (EOF) analysis (Chelton et al. 1990, North et al. 1995) is used to extract the spatial modes of extreme precipitation change. We use the sub-regions according to Li et al. (2011), where rotating EOF (hereafter REOF) analysis is used in partitioning sub-areas. First, the annual precipitation data series of each station is normalized. Principal components analysis is used to extract factors. The REOF method is to rotate the 20 leading factors (with > $85 \%$ accumulative variance contribution) by using varimax orthogonal rotation to make the maximum load in the least variables. Then Euclidean distance and Pearson's correlation coefficient are both used as the measurements of similarity between one station and another in cluster analysis. The results by 2 different measurements are similar in spatial distribution. Given the consistency in one region and differences among regions, as well as the size of each area and the climatic zones used in previous studies (e.g. Wang et al. 2004, Ding et al. 2008, Huang et al. 2011), mainland China is divided into 8 sub-regions. In this study, we selected 5 sub-regions in the eastern part of China, with minor adjustments to the boundaries of each area. The 5 sub-regions are Northeast China (NE) $\left(115-135^{\circ} \mathrm{E}\right.$, $\left.42-52^{\circ} \mathrm{N}\right)$, North China (NC) $\left(105-125^{\circ} \mathrm{E}, 35-42^{\circ} \mathrm{N}\right)$, Jianghuai Region $(\mathrm{JH})\left(105-122^{\circ} \mathrm{E}, 28-35^{\circ} \mathrm{N}\right)$, South China I (SCI) $\left(105-110^{\circ} \mathrm{E}, 20-28^{\circ} \mathrm{N}\right)$ and South China II (SCII) $\left(110-122^{\circ} \mathrm{E}, 20-28^{\circ} \mathrm{N}\right)$. The sub-regions are generally consistent with previous divisions for the eastern part of China. South China was divided into 2 regions, which is different from previous studies.

Power spectrum analysis and linear trend analysis (Wei 1999) are also used in this study.

\section{RESULTS}

\subsection{Climatology of precipitation}

Simulated precipitation gradually decreases with the increment of latitude, especially north of $30^{\circ} \mathrm{N}$, which is similar to the observation (Fig. 2). The spatial correlation coefficient between simulation and observation over Eastern China is 0.77, while the root-mean-square error (RMSE) is $336 \mathrm{~mm}$, a large value. The precipitation in the southern part of eastern China is underestimated, whereas in the northern part it is slightly overestimated. The large RMSE value mainly results from the large negative biases of the southern part of eastern China. The model fails to capture the high value area on the South China coast and sub-high value center in the middle and lower reaches of the Yangtze River Basin. The position of PRCPTOT maximum center is shifted to the east of the Qinghai-Tibet Plateau, which is similar to some models in CMIP3 (Zhang 2008). The result may be due to the resolution, treatment of topography or other reasons (Gao et al. 2006).

The evaluation for summer precipitation simulation based on CMAP monthly precipitation over East Asia shows similar results (Fig. 3). The spatial correlation coefficients between simulated and CMAP summer precipitation over East Asia $\left(105-140^{\circ} \mathrm{E}, 20-45^{\circ} \mathrm{N}\right)$ and most of East China $\left(105-125^{\circ} \mathrm{E}, 20-50^{\circ} \mathrm{N}\right)$ are 0.71 and 0.79 respectively, and the RMSEs are 1.69 and $1.63 \mathrm{~mm} \mathrm{~d}^{-1}$ respectively. The precipitation north of $30^{\circ} \mathrm{N}$ is underestimated. In order to explore the attribution of precipitation biases, several circulation fields were analyzed. The analyses show that the simulated local drier air, weaker water vapor transportation, weaker convergence and weaker upward motion contribute to underestimating precipitation over this area.

Fig. 3a shows that the local integrated water vapor in summer in most of Eastern China is underestimated by BCC_CSM1.0, with minimum values below $-12 \mathrm{~kg} \mathrm{~m}^{-2}$. Over East Asia, the correlation coefficient between simulation and NCEP reanalysis is 0.94 and the RMSE is $4.12 \mathrm{~kg} \mathrm{~m}^{-2} ; 51 \%$ of the grids have consistent signs between precipitation biases and precipitable water biases.

Fig. 3b shows that the vertical integrated water vapor flux over most of the $105-140^{\circ} \mathrm{E}, 20-32^{\circ} \mathrm{N}$ area is underestimated with southward transportation bias. The consistency of signs between precipitation biases and vertical integrated water vapor flux biases is $75 \%$, which indicates the contribution of water vapor transportation to precipitation biases. Thus the capability of the model in simulating water vapor flux is more important for precipitation simulation in summer over East Asia.

The dynamic factor is also important for precipitation formation. Fig. 4 shows the longitude-height section for divergence in summer over $20-30^{\circ} \mathrm{N}$. 

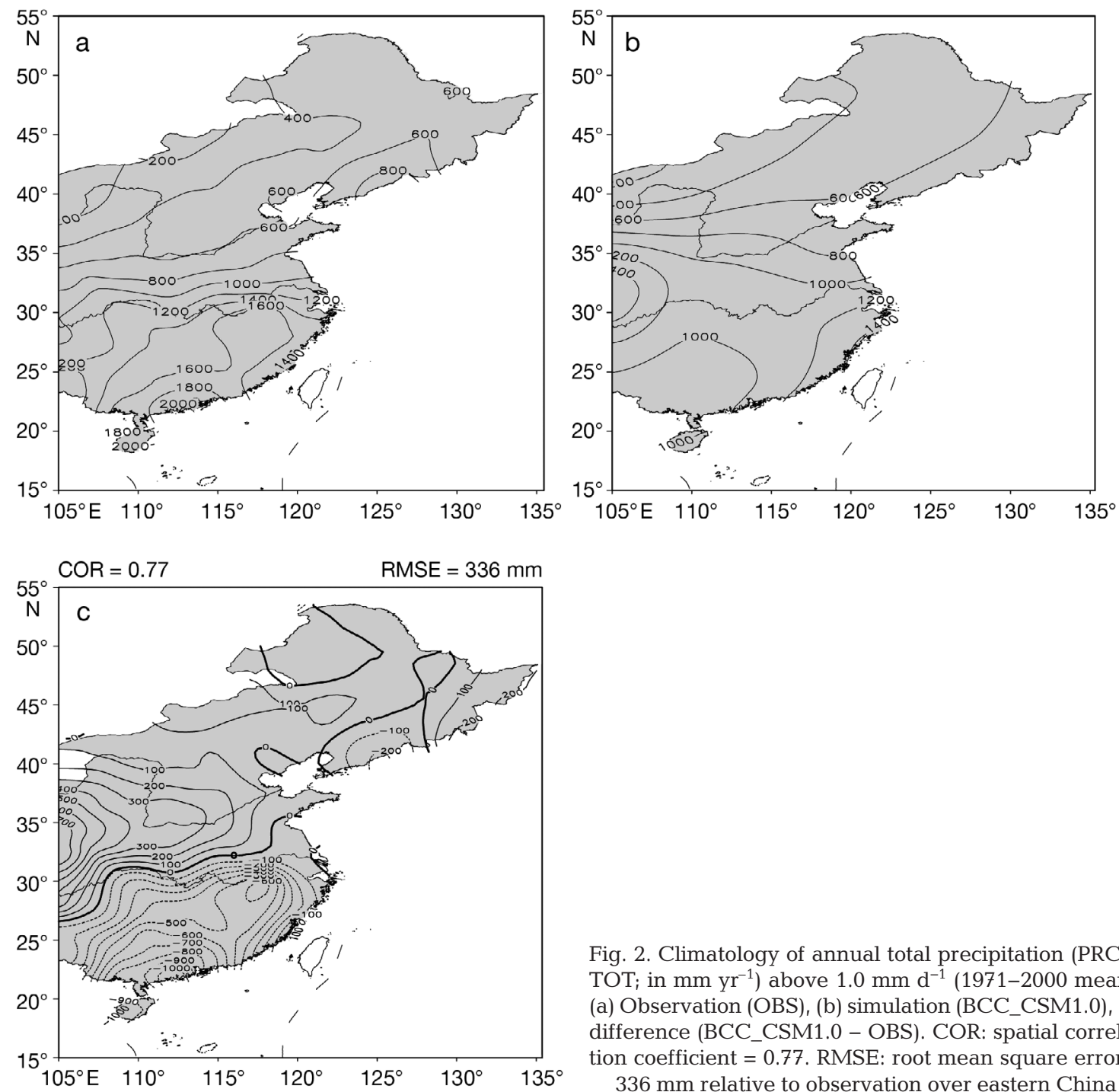

Fig. 2. Climatology of annual total precipitation (PRCPTOT; in $\mathrm{mm} \mathrm{yr}^{-1}$ ) above $1.0 \mathrm{~mm} \mathrm{~d}^{-1}$ (1971-2000 mean). (a) Observation (OBS), (b) simulation (BCC_CSM1.0), (c) difference (BCC_CSM1.0 - OBS). COR: spatial correlation coefficient $=0.77$. RMSE: root mean square error $=$

$336 \mathrm{~mm}$ relative to observation over eastern China

Negative values denote convergence and positive values denote divergence. The height of convergence can be up to $400 \mathrm{hPa}$ in NCEP reanalysis, while it is only up to $500 \mathrm{hPa}$ in the BCC_CSM1.0 simulation (Fig. 4). The specific values at the lower levels are greater in the simulation than in the reanalysis field, which implies that the simulated convective activity is weaker over this area. The simulated upward vertical velocities over this area are less than the observed ones, which implies that the upward motion is weaker and the deep convection may be underestimated in BCC_CSM1.0 (data not shown). The analysis for outgoing longwave radiation supports this point to some extent (data not shown).

Fig. 5 shows the bias in frequency of rain for the 1971-2000 mean simulated by BCC_CSM1.0. Fig. 5a indicates that rainy days with light precipitation are overestimated over eastern China. The biases are

$>90 \mathrm{~d}$ over most of eastern China and even up to $180 \mathrm{~d}$ in the coastal area of South China. Fig. 5b shows that moderate rainy days are underestimated south of the Yangtze River and in the northeast, but overestimated over the other regions. The maximum positive bias is $>20 \mathrm{~d}$, which is located at the eastern side of the Qinghai-Tibet Plateau. There is a positive bias in the mid-lower reaches of the Yellow River Basin, with the maximum $>10 \mathrm{~d}$. The negative bias center is located in South China, and the value is less than $-10 \mathrm{~d}$.

For heavy rain (Fig. 5c), the rainy days are underestimated over most areas of eastern China except some regions in the Yellow River Basin. There are maximum biases (below $-10 \mathrm{~d}$ ) in the South China coastal area. A negative bias center lies in the south of the Yangtze River Basin, with the center values below $-8 \mathrm{~d}$. The maximum deviation in the northeast is below $-2 \mathrm{~d}$. For rainstorm and heavy rainstorm, the 


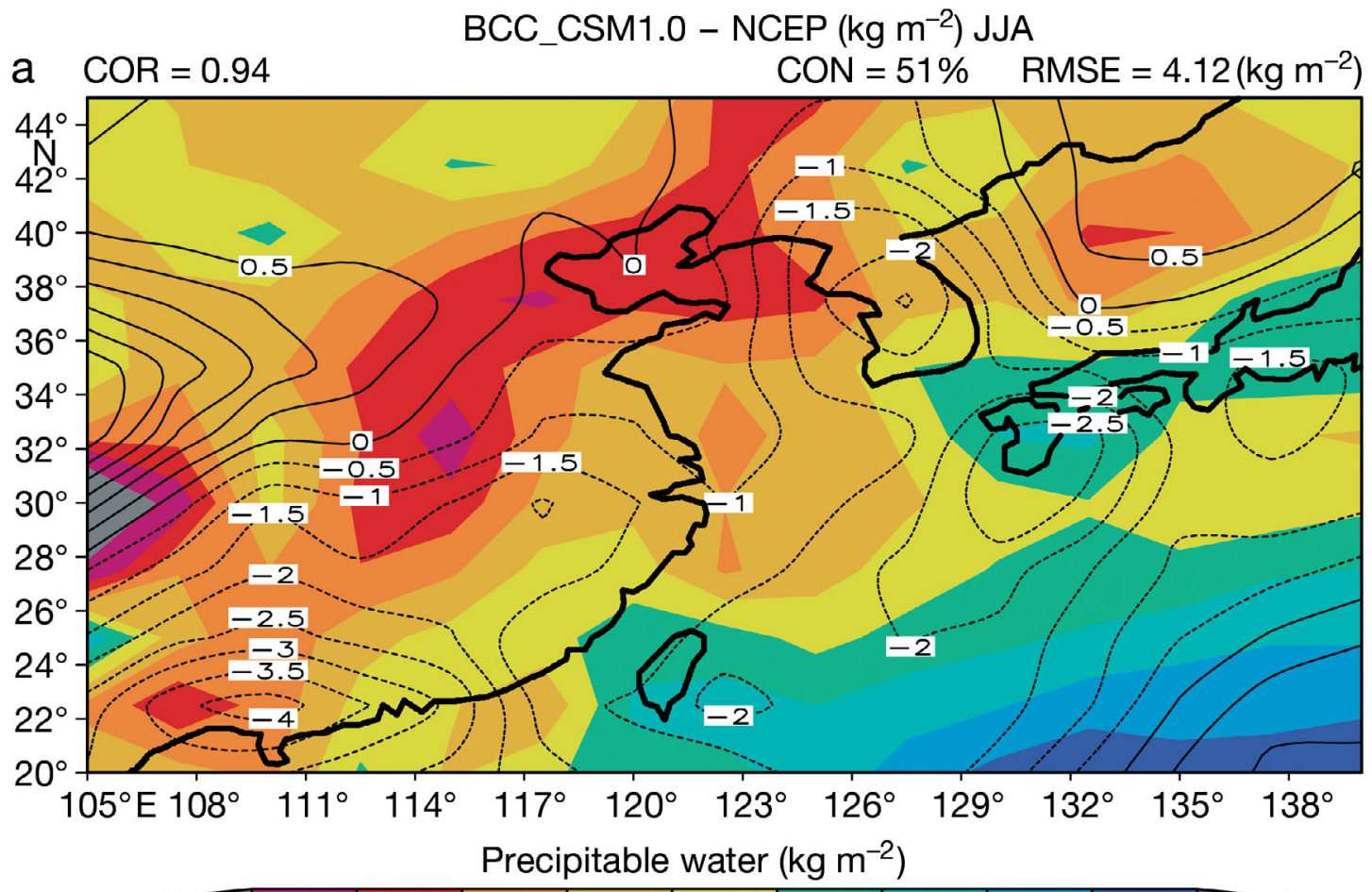

\begin{tabular}{llllllllll|l} 
& & & & & & $\mid$ & & $\mid$ & 1 \\
-12 & -8 & -6 & -4 & -2 & 0 & 2 & 4 & 6 & 8
\end{tabular}

b BCC_CSM1.0 - NCEP(1980-1999) $\left(\mathrm{kg} \mathrm{m}^{-1} \mathrm{~s}^{-1}\right) \mathrm{JJA} \quad$ CON $=75 \%$

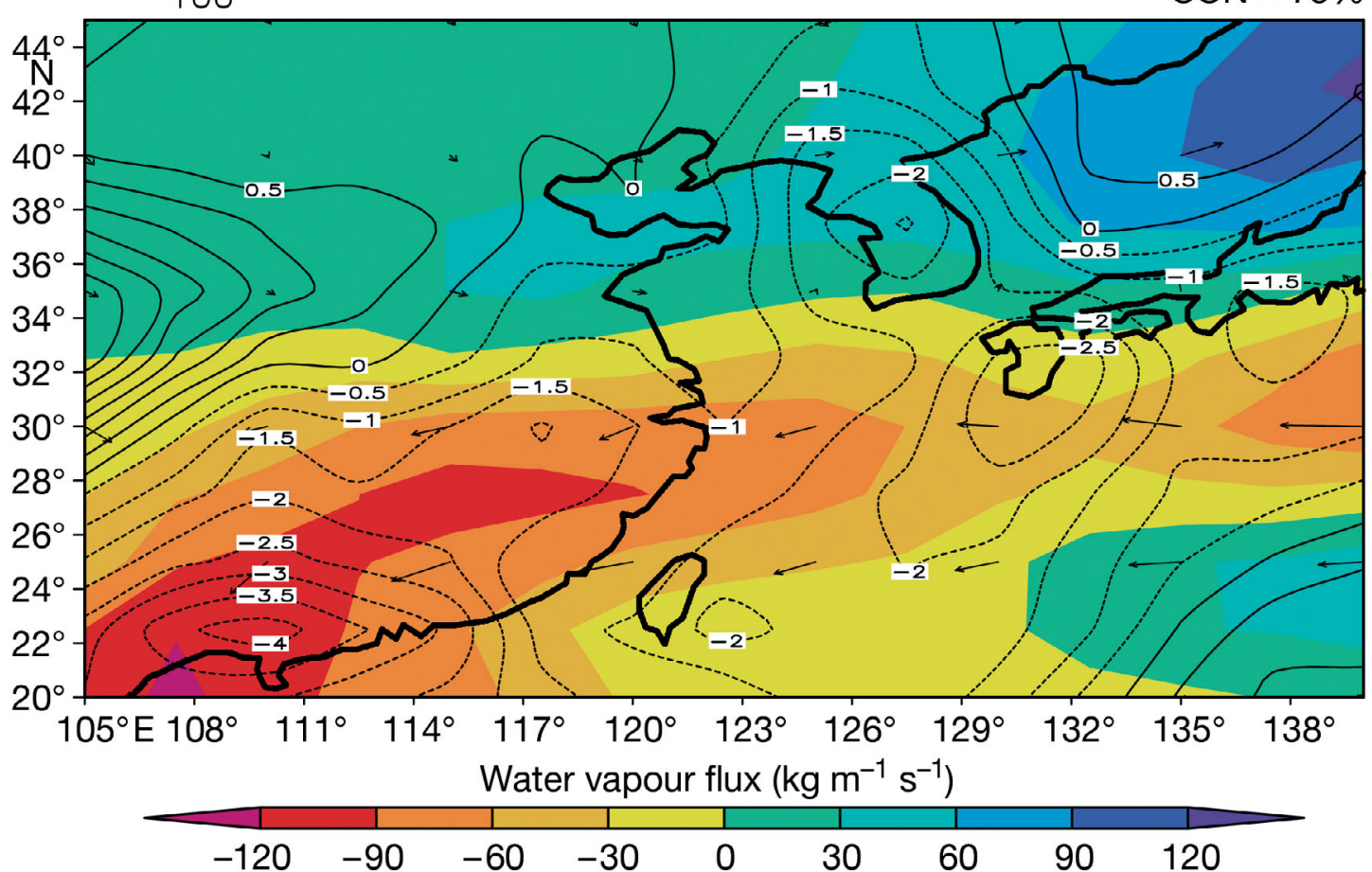

Fig. 3. Biases of simulated precipitation (BCC_CSM1.0 data - CMAP data; contours in $\mathrm{mm} \mathrm{d}^{-1}$ ), and (a) atmospheric total precipitable water (in color; $\mathrm{kg} \mathrm{m}^{-2}$ ) and (b) vertical integrated water vapor flux (in color and vectors; $\mathrm{kg} \mathrm{m}^{-1} \mathrm{~s}^{-1}$ ) in Jun-Aug (JJA) of 1980-1999 (BCC_CSM1.1 data - NCEP reanalysis data). COR: correlation coefficient between simulated and NCEP reanalysis data (colored areas). RMSE: root mean square error of simulated precipitable water relative to reanalysis data. CON: consistent rates of the biases fields between precipitation and precipitable water or water vapor flux. Precipitation is calculated based on the CMAP monthly precipitation data; circulation fields are calculated based on monthly NCEP I reanalysis data by NCAR 

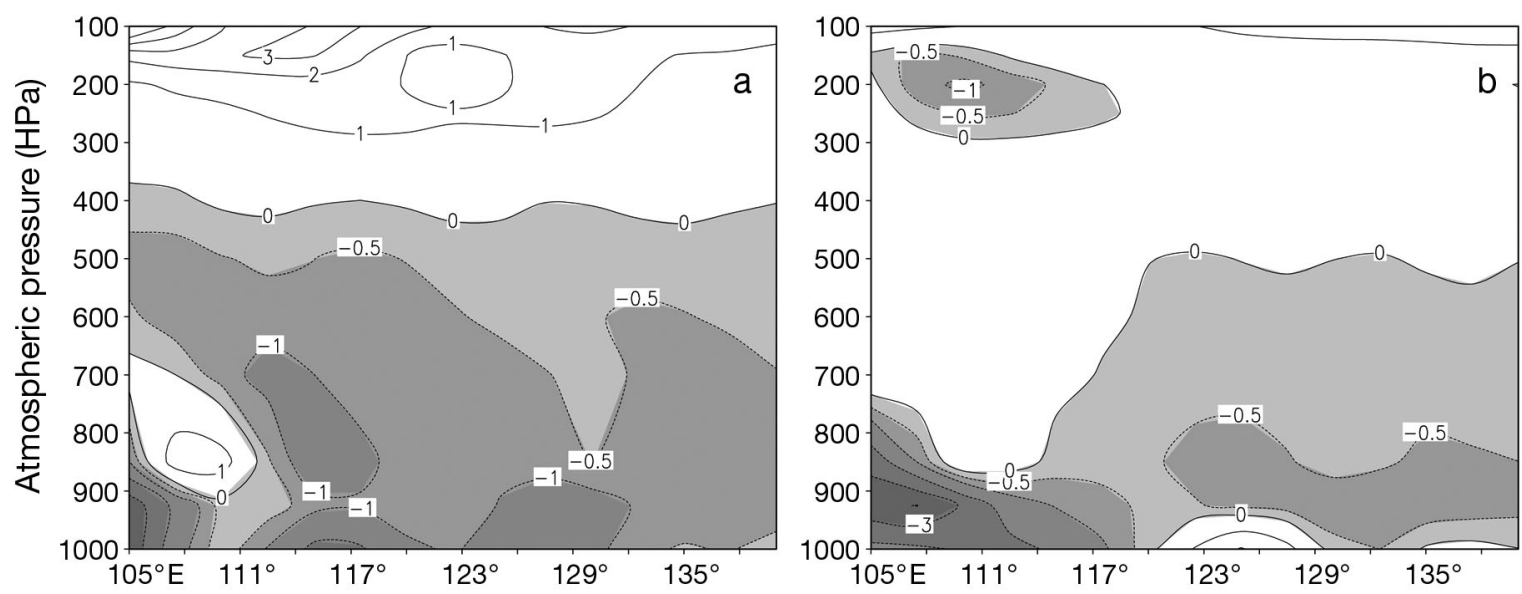

Fig. 4. Zonal averaged (a) observed and (b) simulated divergence $\left(10^{-6} \mathrm{~s}^{-1}\right)$ over $20-30^{\circ} \mathrm{N}$ in Jun-Aug for $1971-2000$

rainy days are all underestimated over almost the whole of eastern China (Fig. 5d,e).

The result is similar to the evaluation of models under CMIP3 by Sun et al. (2006). The models under CMIP3 also underestimated the frequency of heavy or even stronger precipitation events. The precipitation event with a much larger precipitation amount is often related to the stronger or deep convection activity. The weaker circulation may have an important contribution to the negative biases of heavy precipitation frequency in BCC_CSM1.0.

\subsection{Climatology of thresholds, frequency and amount of extreme precipitation}

Considering the large spatial difference of precipitation and also the bias of BCC_CSM1.0 in simulating the absolute rainfall, we use the percentile method to define the extreme precipitation event. Here we select the 95th percentile to calculate the threshold and related statistics.

Fig. 6 shows the observed and simulated thresholds of extreme precipitation events at the 95th percentile for 1971-2000. The observation shows that there are 3 high-value areas in the South China coast, the middle and lower reaches of the Yangtze River Basin and North China. The maximum in South China is $>40 \mathrm{~mm} \mathrm{~d}^{-1}$, and those in North China and the middle and lower reaches of the Yangtze River Basin are up to $28 \mathrm{~mm} \mathrm{~d}^{-1}$ (Fig. 6a).

A comparison between simulation and observation reveals that the spatial correlation coefficient is 0.74 . The model reproduces the high value areas of thresholds located in the South China coastal area and North China, but the maximum values are underestimated, up to 18 and $16 \mathrm{~mm} \mathrm{~d}^{-1}$, respectively, and the biases are -28 and $-12 \mathrm{~mm} \mathrm{~d}^{-1}$, respectively. The simulation fails to capture the observed high value center in the middle and lower reaches of the Yangtze River Basin, as well as a little westward deflection from Bohai Coast to central North China for the second high value center (Fig. 6b). The RMSE of the simulation over eastern China is $10.5 \mathrm{~mm} \mathrm{~d}^{-1}$. Generally, the model reproduces the high-low value distribution of the threshold, although there are negative biases in the whole of eastern China.

Fig. 7 shows the observed and simulated climatology of R95p, as well as the biases of simulated R95p. The spatial correlation coefficient between simulation and observation is 0.65 . In observation, the high frequency area is located in South China with the maximum $>10 \mathrm{~d}$. In simulation, however, the high frequency center is shifted northward to the middle and lower reaches of the Yangtze River Basin, with maxima $>12 \mathrm{~d}$. Moreover, there is another higher frequency area in the east side of the Qinghai-Tibetan Plateau due to the large bias in precipitation simulation. The simulated R95p are greater than the observation in most of eastern China except in local areas in South China. The area with largest biases is located in the east side of the Qinghai-Tibetan Plateau and the biases are also much larger in some local areas between the Yellow River and Yangtze River.

Based on the above analysis, the annual total extreme precipitation above the 95th percentile is calculated. Fig. 8a,b shows the observed climatology (1971-2000 mean) of R95pTOT and its proportion in PRCPTOT. The spatial distribution of R95pTOT is similar to PRCPTOT (Fig. 2) over Eastern China, with the characteristic of gradual decrease from south to north. The annual R95pTOT is $>1000 \mathrm{~mm}$ in the South China coast and $<100 \mathrm{~mm}$ in central Inner Mongolia. The percentages of R95pTOT in PRCPTOT are $>45 \%$ 

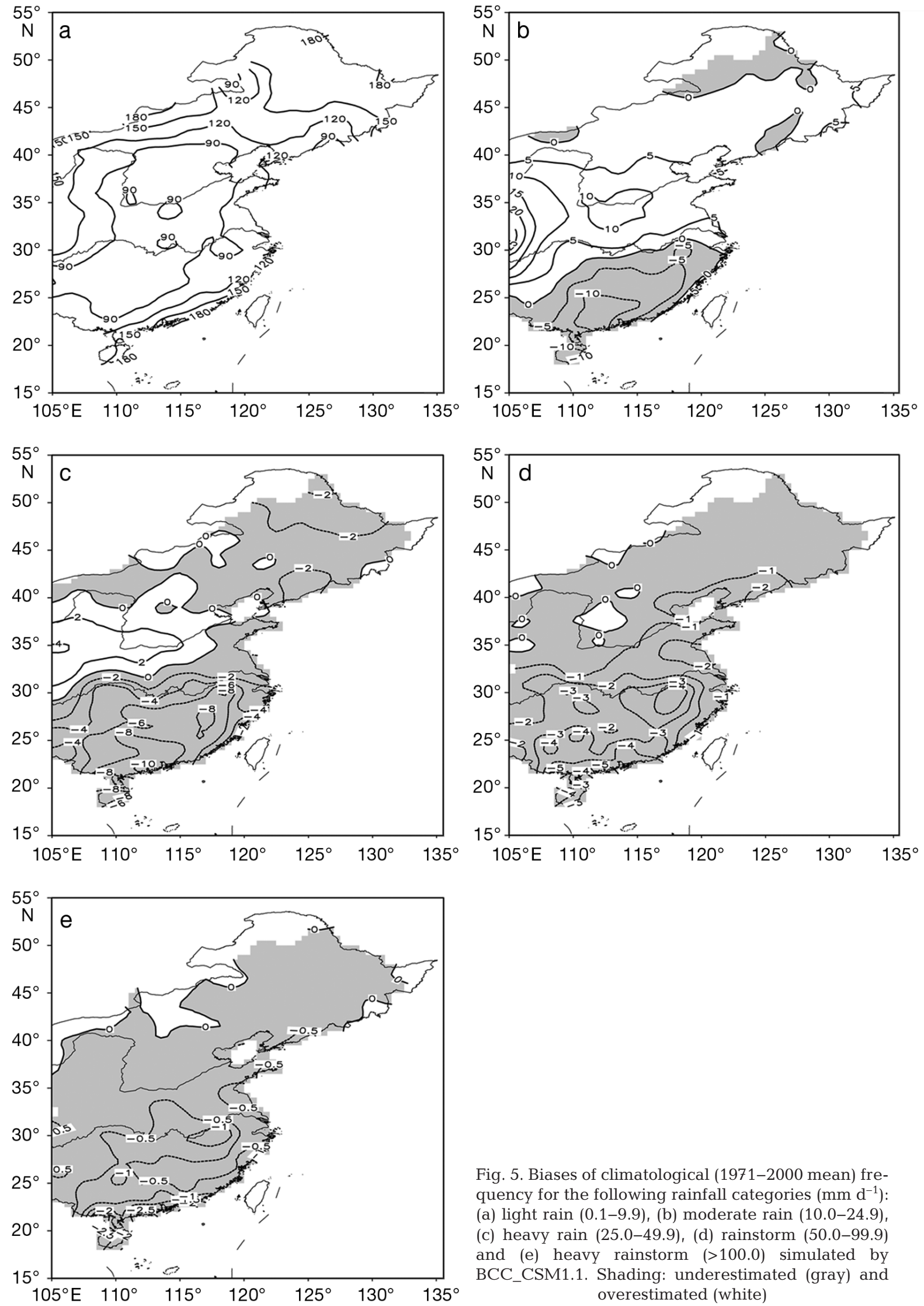

Fig. 5. Biases of climatological (1971-2000 mean) frequency for the following rainfall categories $\left(\mathrm{mm} \mathrm{d}^{-1}\right)$ : (a) light rain (0.1-9.9), (b) moderate rain (10.0-24.9), (c) heavy rain (25.0-49.9), (d) rainstorm (50.0-99.9) and (e) heavy rainstorm (>100.0) simulated by BCC_CSM1.1. Shading: underestimated (gray) and overestimated (white) 

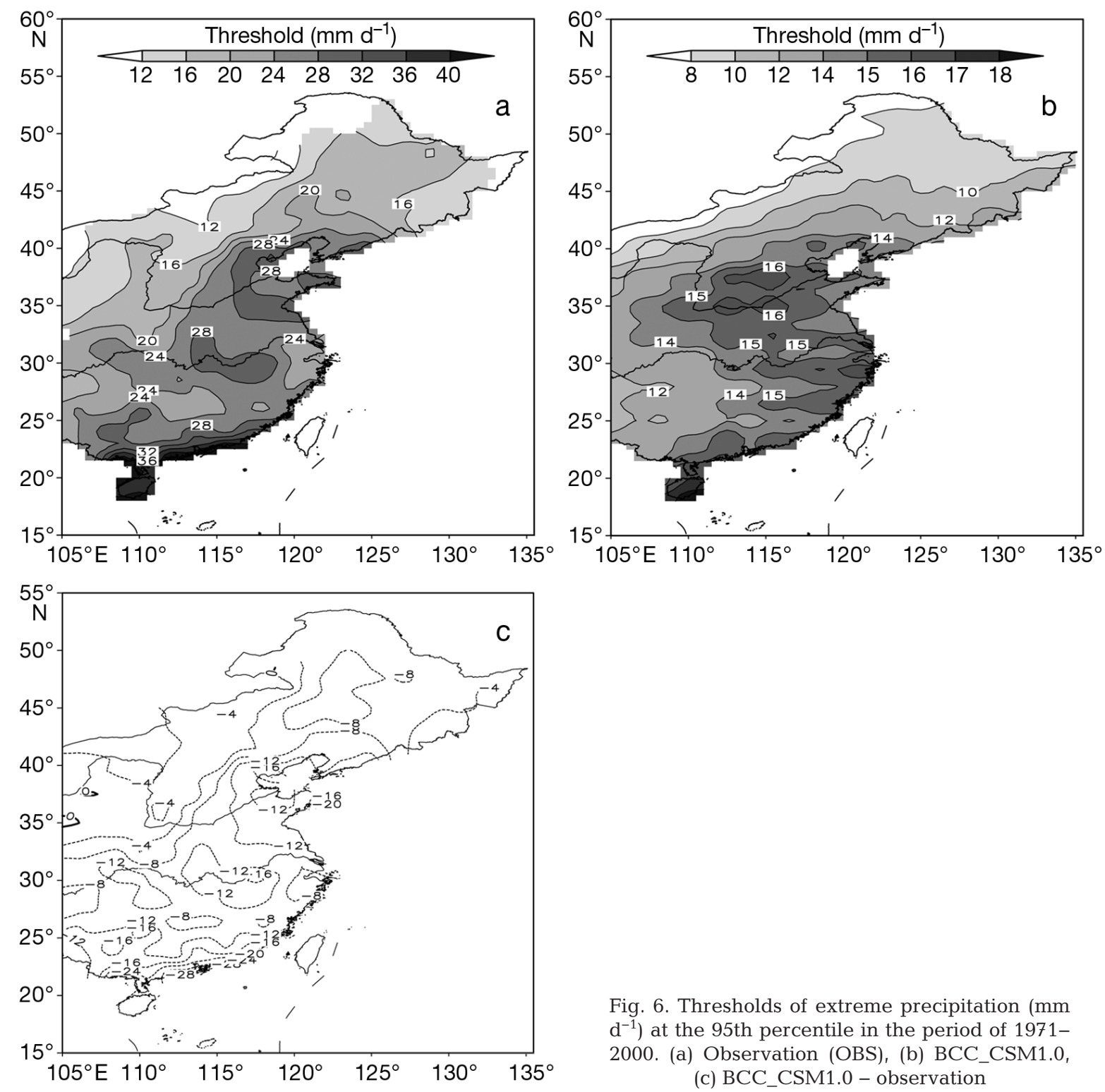

Fig. 6. Thresholds of extreme precipitation (mm $\mathrm{d}^{-1}$ ) at the 95th percentile in the period of 19712000. (a) Observation (OBS), (b) BCC_CSM1.0, (c) BCC_CSM1.0 - observation

in most of eastern China, except for Inner Mongolia $(<36 \%)$, with the higher value area in South China (up to $50 \%$ ) and gradually decreasing from south to north. The high portion of extreme precipitation is determined by the method to calculate the threshold.

Fig. 8c shows the simulated climatology of R95pTOT by BCC_CSM1.0. The simulated R95pTOT north of $32.5^{\circ} \mathrm{N}$ is greater than the observation, especially in the central area between the mid-upper reaches of the Yellow River and Yangtze River. The simulation south of the Yangtze River, however, is lower than the observation, especially in the South China coastal area, with the negative biases $(<-500 \mathrm{~mm})$ in the center (Fig. 8e). Fig. 8d shows the percentage of R95pTOT in PRCPTOT simulated by BCC_CSM1.0. The simulated percentages of R95pTOT in PRCPTOT are similar to observation in magnitude. There is a high value center in the middle and lower reaches of the Yellow River Basin, which is larger than the observation. The simulated percentage values in South China, middle reaches of Yangtze River Basin and the north part of Northeast are slightly lower than the observation, and most of the bias values are $<4 \%$ (Fig. 8f).

\subsection{Spatial feature of extreme precipitation amount change}

Observed (Fig. 9a-c) and simulated (Fig. 9d-f) EOF modes for R95pTOT change were calculated for 1956-2009. 

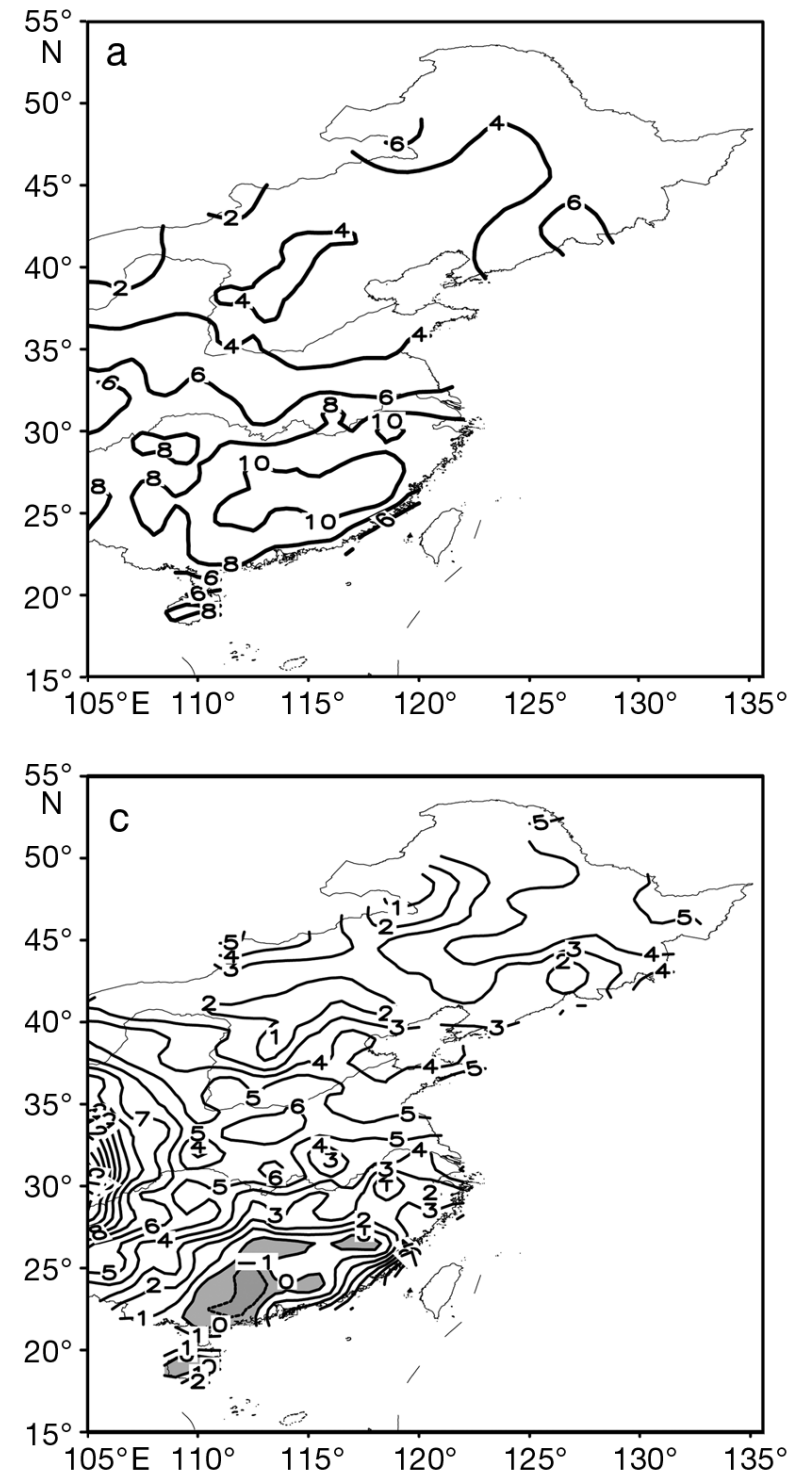

EOF1 of observed R95pTOT (Fig. 9a) shows that the change of R95pTOT south of the Yangtze River has the same tendency as that over the middle part of Inner Mongolia and the local area of the northeast, and opposite to that north of the Yangtze River. EOF1's variance contribution is $9.4 \%$. The first EOF mode of T95pTOT simulated by BCC_CSM1.0 captures the main spatial pattern for observed R95pTOT change (Fig. 9d), although parts of the negative area in the southern part of the Yangtze River expands northwards to the Huaihe River Basin. The variance contribution of EOF1 is $11.8 \%$, which is greater than observations.

EOF2 of observed R95pTOT (Fig. 9b) shows that the change tendency over most of the Yellow River Basin area is similar to that in the South China coast.

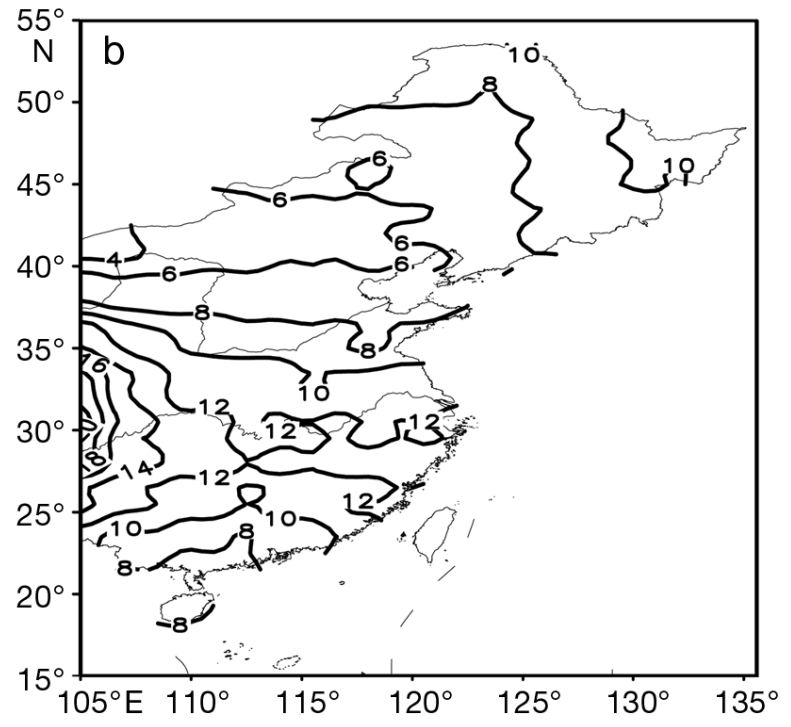

Fig. 7. Climatology (1971-2000 mean) of number of days with rainfall above the 95th percentile (R95p). (a) Observation (OBS), (b) BCC_CSM1.0, (c) BCC_CSM1.0 - observation (gray: underestimated, white: overestimated by the simulation). Unit: $d$

However, the northeast and the area between 25 and $35^{\circ} \mathrm{N}$ in eastern China show the opposite trend. The variance contribution is $7.5 \%$. The EOF2 of R95pTOT simulated by BCC_CSM1.0 also captures the general observed characteristics, although there is some difference in spatial extension (Fig. 9e). The variance contribution is $8.5 \%$.

EOF3 mode of observed R95pTOT (Fig. 9c) is characterized by the opposite change tendency between the Jianghuai area and other areas of eastern China. Its variance contribution is $7.4 \%$. The EOF3 mode of simulated R95pTOT (Fig. 9f) is characterized by an opposite change trend between the local area in the mid-lower reaches of the Yangtze River Basin and most other areas in eastern China, which is generally similar to the observation. There is a difference be- 

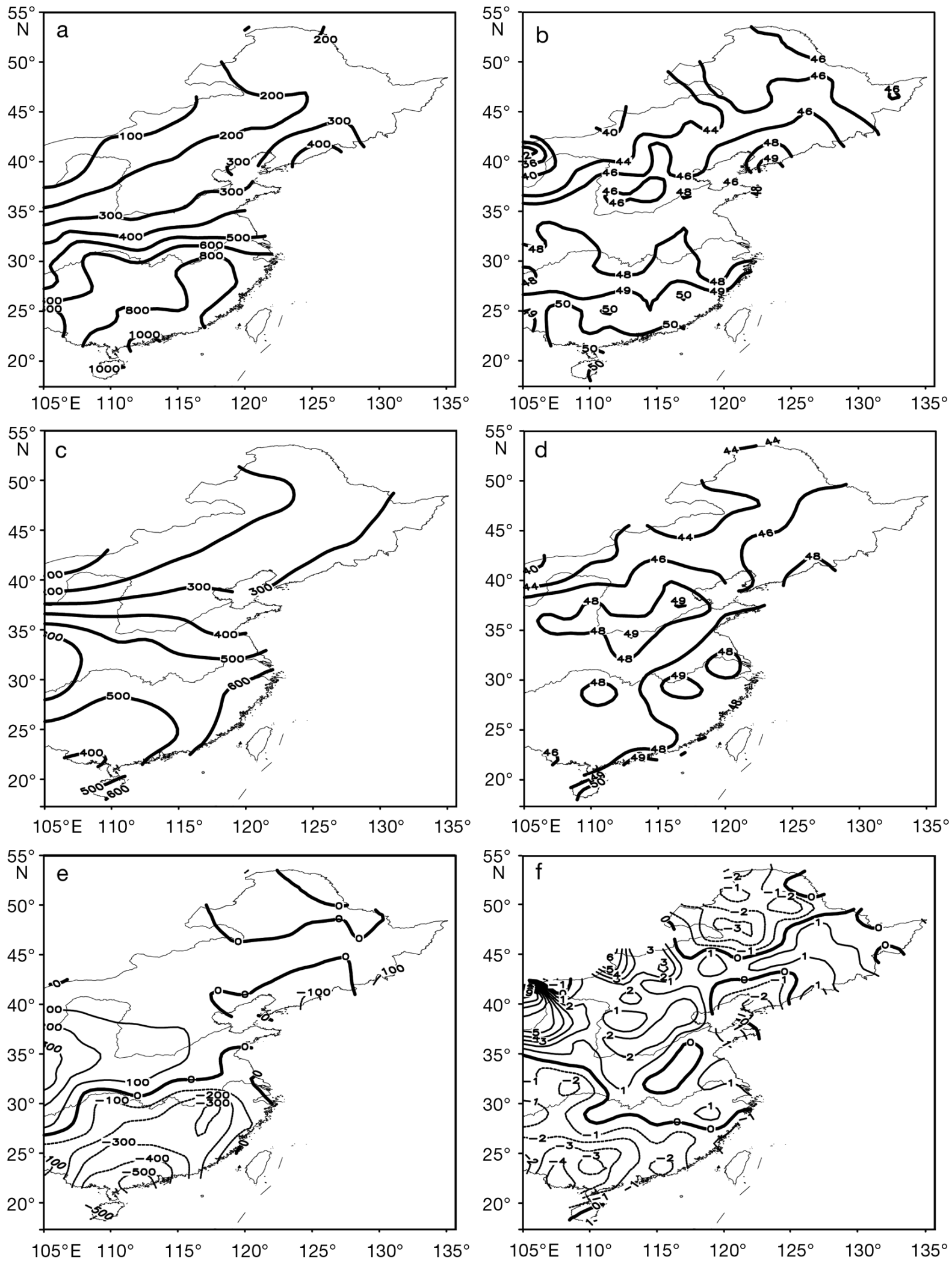

Fig. 8. Distribution of climatology (1971-2000 mean) for (a,c) total rainfall above the 95th percentile (R95pTOT; mm), (b,d) R95pTOT as a percentage of total precipitation (PRCPTOT) and $(\mathrm{e}, \mathrm{f})$ the biases fields. $(\mathrm{a}, \mathrm{b})$ Observation $(\mathrm{OBS})$, (c,d) BCC_CSM1.0 

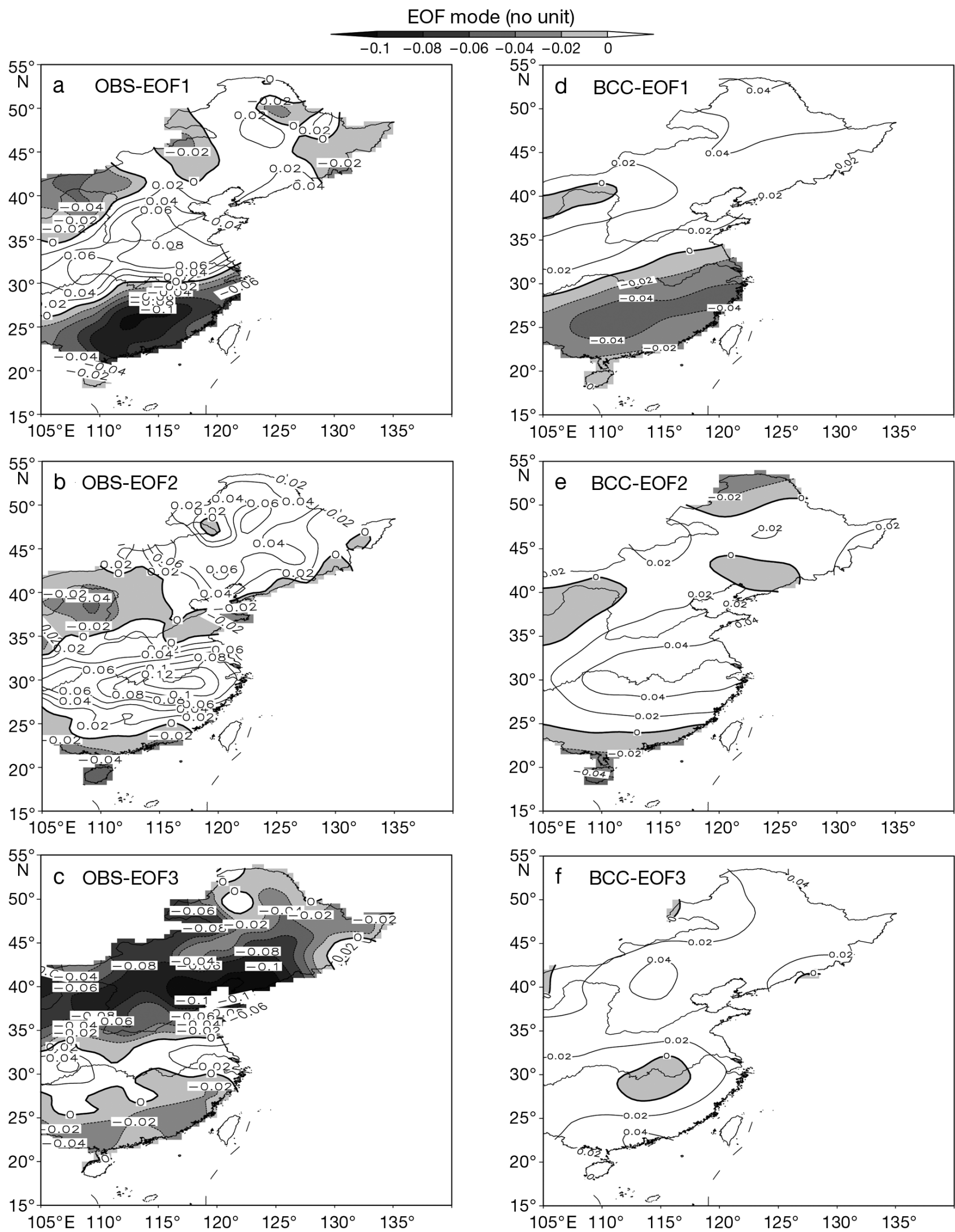

Fig. 9. The first 3 leading Empirical Orthogonal Function (EOF) modes for annual total rainfall above the 95th percentile (R95pTOT) during 1956-2009. (a-c) Observation, (d-f) BCC_CSM1.0. (a,d) EOF1, (b,e), EOF2, (c,f) EOF3 
tween simulation and observation along the middle and lower Yangtze River Basin and weaker change signals in North China. The variance contribution of EOF3 is $8.0 \%$, which is greater than observations.

Generally speaking, although BCC_CSM1.0 has obvious systematical biases in extreme precipitation indices, the model can reasonably capture the general long term change patterns of R95pTOT.

\subsection{Long term trend of extreme precipitation}

To analyze the performance of BCC_CSM1.0 in simulating the long term trend of extreme precipitation events, linear trend analysis and the nonparametric Mann-Kendall test were used.

Fig. 10 shows the linear trend coefficient of R95pTOT, R95p, R95pI, and SDII during 1956-2009. The spatial distributions of linear trends of R95pTOT, R95p, R95pI, and SDII are similar, with opposite linear trend coefficients between the north $(-)$ and south (+) of $\sim 33^{\circ} \mathrm{N}$, but with more positives in northern areas for R95pI and SDII. The results are similar to previous research (Pan 2002, Zhai et al. 2005, Dong et al. 2011).

BCC_CSM1.0 captures the negative trends of R95pTOT, R95p, and SDII in the northeast, as well as the positive trends for R95pTOT, R95p, R95pI, and SDII in the mid-lower reaches of the Yangtze River Basin (Table 1). But the model fails to capture the negative trend of R95pI in the northern area. The opposite linear trends of the 4 indices over most or part of southern China indicate that the model has poor performance in simulating the long term linear trend of extreme precipitation over this area. The regional averaged anomalies of proportion of R95pTOT and R95p during the period of 1956-2009 were calculated. As for R95pTOT, there is a significant 36-yr period in NE China and a 2.8 yr period in North China. No significant period is detected in Jianghuai, South China I, and South China II. The simulation shows a significant $12 \mathrm{yr}$ period in NE China, which is shorter than observed, and no significant period in the other 4 sub-regions. As for observed R95p, there is a significant $36 \mathrm{yr}$ period in NE China and 2.8 and 2.6 yr periods in North China. No significant period is detected in Jianghuai, South China I and South China II. The result reveals that there is a significant $12 \mathrm{yr}$ period in NE China, which is shorter than observation. A significant $2.8 \mathrm{yr}$ period is detected in South China I. No significant period is detected in the other 3 subregions.
The Mann-Kendall test for observed regional averaged percentage of R95pTOT (Table 1) shows that there are significantly decreasing trends at the 0.1 significance level in NE China and North China, and increasing trends in Jianghuai, South China I and South China II, but the increasing trends are not significant. BCC_CSM1.0 captures the decreasing and increasing trends in NE China and Jianghuai respectively for R95TOT, although the tendencies are weaker. The trends, however, are opposite in North China, South China I, and South China II for both of simulated R95TOT and R95p.

As for observation, the regional averaged R95p in North China has a significant decreasing trend at the 0.05 significance level. The R95p in NE China decreased but the tendency is not significant. Those in Jianghuai, South China I and South China II have increased in some extent. The result in North China is similar to previous studies (Zhai et al. 2005, Dong et al. 2011), and that in southern China is similar to that shown in Zhai et al. (2005). BCC_CSM1.0 captures the decreasing and increasing trends in NE China and Jianghuai for R95p, with weaker tendencies. The trends, however, are opposite in North China, South China I and South China II for R95p in the simulation.

\subsection{Interdecadal change of extreme precipitation frequency}

Observation analysis showed interdecadal change in the summer climate in East Asia at the end of the 1970s (Hu 1997), and an abrupt change for summer precipitation in South China (Ding et al. 2008). Probability density analysis was used to explore the regional interdecadal change of extreme precipitation frequency in the 5 sub-regions, which has not been analyzed in previous work. Here we selected 19561979 and 1980-2009 as 2 periods for interdecadal analysis in NE China, North China and Jianghuai. In addition, we selected 1956-1979, 1980-1992, and 1993-2009 as 3 periods for interdecadal analysis in South China I and South China II. Probability density of R95p was calculated for each period in each subregion (Fig. 11), and the spatio-temporal mean during the 2 or 3 periods for the 5 sub-regions are listed in Table 2. Generally, the frequency of extreme precipitation above the 95th percentile in simulation is higher than that in observation in each sub-region.

In NE China, the model is able to capture the increment of the regional averaged decadal mean of R95p. The observed spatio-temporal averaged frequency 

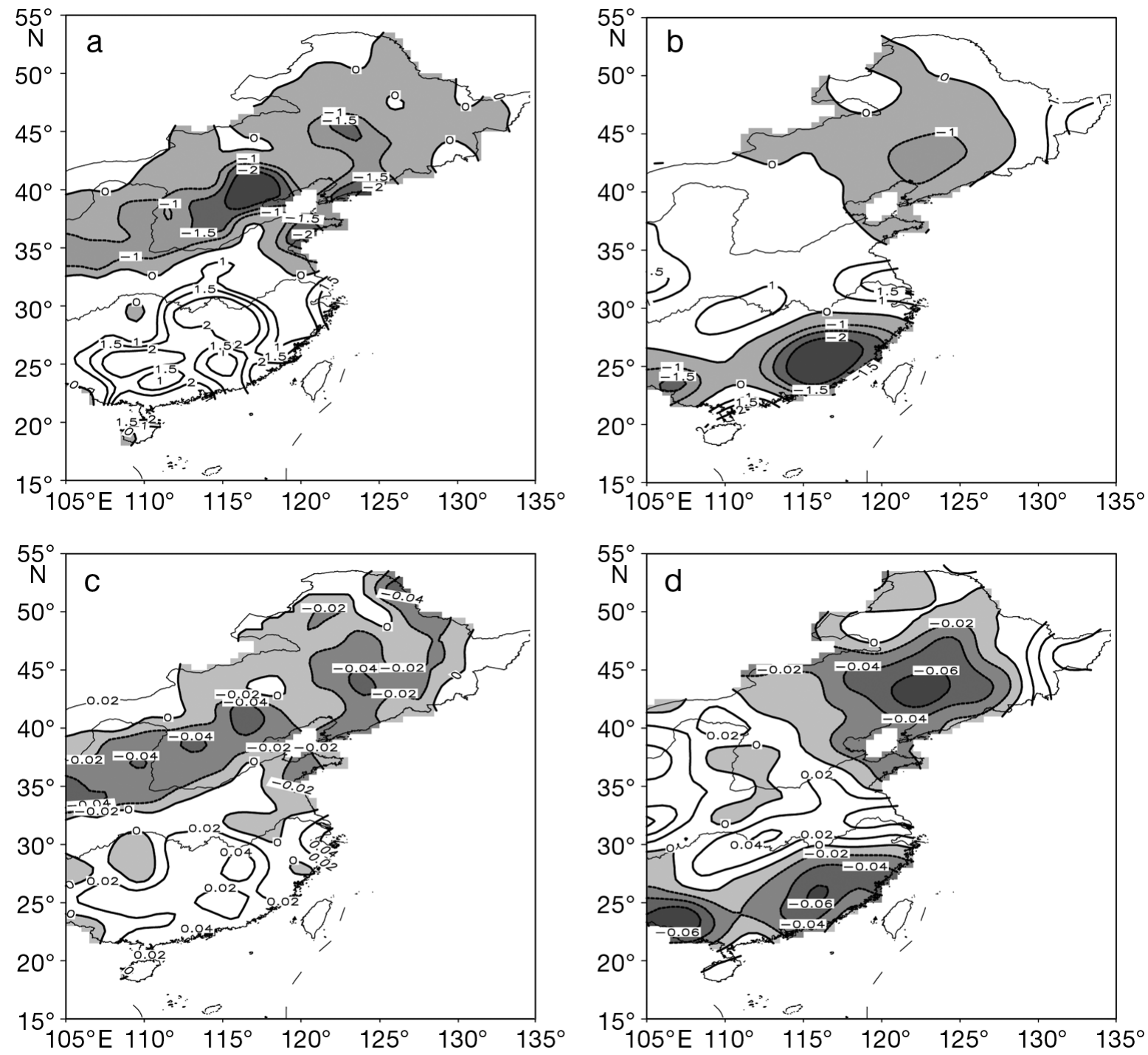

Fig. 10. Linear trends for $(a, b)$ total rainfall above the 95th percentile (R95pTOT; mm decade $\left.{ }^{-1}\right)$, (c,d) number of days with rainfall above the 95 th percentile $\left(R 95 p ; d\right.$ decade $\left.{ }^{-1}\right),(e, f)$ intensity index of the extreme precipitation $\left(\mathrm{R}^{2} \mathrm{pI}\right.$ mm $\mathrm{d}^{-1}$ decade $\left.^{-1}\right)$, and $(g, h)$ daily precipitation intensity index (SDII $\mathrm{mm} \mathrm{d}^{-1}$ decade $^{-1}$ ) over eastern China during $1956-2009$. $(\mathrm{a}, \mathrm{c}, \mathrm{e}, \mathrm{g})$ Observation (OBS), (b,d,f,h) BCC_CSM1.0

increases from 7.41 to 7.64 and the simulated results change from 20.36 to 21.18 . The model also captures the increment in higher frequency range and decrement in mid frequency range but it fails to capture the decrement in the lower frequency range.

In North China, the model shows inability in simulating the interdecadal change of R95p. Fig. 10b shows that the observed probability density curve of R95p shifts to a lower frequency and the spatio-temporal mean value decreases from 6.62 to 6.08 . However, there is no obvious change in the simulation (Fig. 11g), with similar values in both time periods.

In the Jianghuai area, BCC_CSM1.0 reproduces the general shift of the probability density curve from a lower frequency range to a higher one. The spatiotemporal mean increases in observations and in simulation, but the simulated spatio-temporal mean frequencies are higher than observations.

In South China I, the probability density curve has a slight shift from a higher frequency range to the lower one from 1956-1979 to 1980-1992 in the simulation, with the regional R95p mean decreasing. The change is similar to the observations. The model generally fails to reproduce the observed shift from a lower to a higher frequency range from 1980-1992 to 1993-2009. The regional averaged R95p value in observations increases, while that in simulation just has a slight increase. 

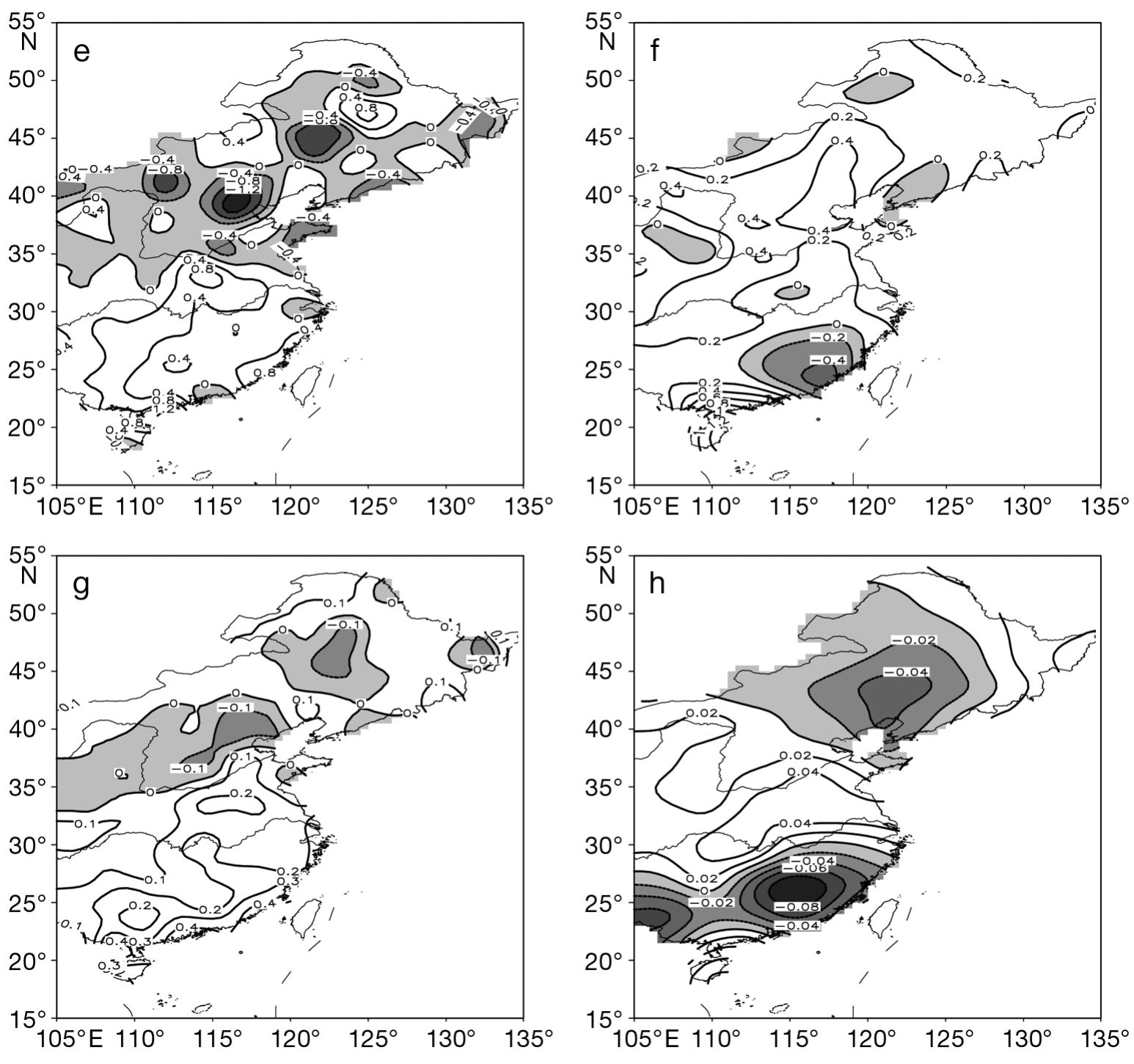

Fig. 10 (continued)

Table 1. Mann-Kendall trend testing for observed (OBS) and simulated (BCC) total rainfall above the 95th percentile (R95pTOT) and number of days with rainfall above the 95th percentile (R95p) for the 5 sub-regions. $\beta$ : magnitude of the trend (Eq. 6); $Z_{c}$ : test of significance (Eq. 2); $\left|Z_{0.1}\right|=1.64,\left|Z_{0.05}\right|=1.96$

\begin{tabular}{|lrrrr|}
\hline Region & \multicolumn{2}{c}{ OBS } & \multicolumn{2}{c|}{ BCC } \\
& $\beta$ & \multicolumn{1}{c}{$Z_{\mathrm{c}}$} & \multicolumn{1}{c}{$\beta$} & $Z_{\mathrm{c}}$ \\
\hline R95pTOT $\left(\% \mathbf{~ y r}^{-\mathbf{1}}\right.$ ) & & & & \\
NE China & -0.300 & -1.69 & -0.074 & -0.33 \\
North China & -0.405 & -1.75 & 0.128 & 0.60 \\
Jianghuai & 0.075 & 0.66 & 0.195 & 1.15 \\
South China I & 0.138 & 1.28 & -0.036 & -0.18 \\
South China II & 0.250 & 1.45 & -0.229 & -1.13 \\
R95p (d yr $^{-1}$ ) & & & & \\
NE China & -0.018 & -1.46 & -0.016 & -0.57 \\
North China & -0.019 & -1.98 & 0.003 & 0.10 \\
Jianghuai & 0.003 & 0.16 & 0.035 & 1.12 \\
South China I & 0.006 & 0.37 & -0.033 & -0.84 \\
South China II & 0.024 & 1.0 & -0.039 & -0.98 \\
\hline
\end{tabular}

In South China II, the observed extreme precipitation events above the 95th percentile become more frequent from 1956-1979 to 1980-1992 and 19932009. However, the simulated spatio-temporal averaged value of R95p tends to decrease. The change is opposite to the observations. The interdecadal tendency is similar to the observations. Generally, the BCC_CSM1.0 does not reproduce the interdecadal change feature of R95p in South China II.

The observed increment of extreme precipitation over South China since 1993 is similar to the work of Ning \& Qian (2009). Here South China is divided into 2 sub-regions and one can find the differences between South China I and South China II. The R95p decreased in South China I, but increased in South China II from 1956-1979 to 1980-1992. The mechanism which causes the difference needs to be studied in future work. 

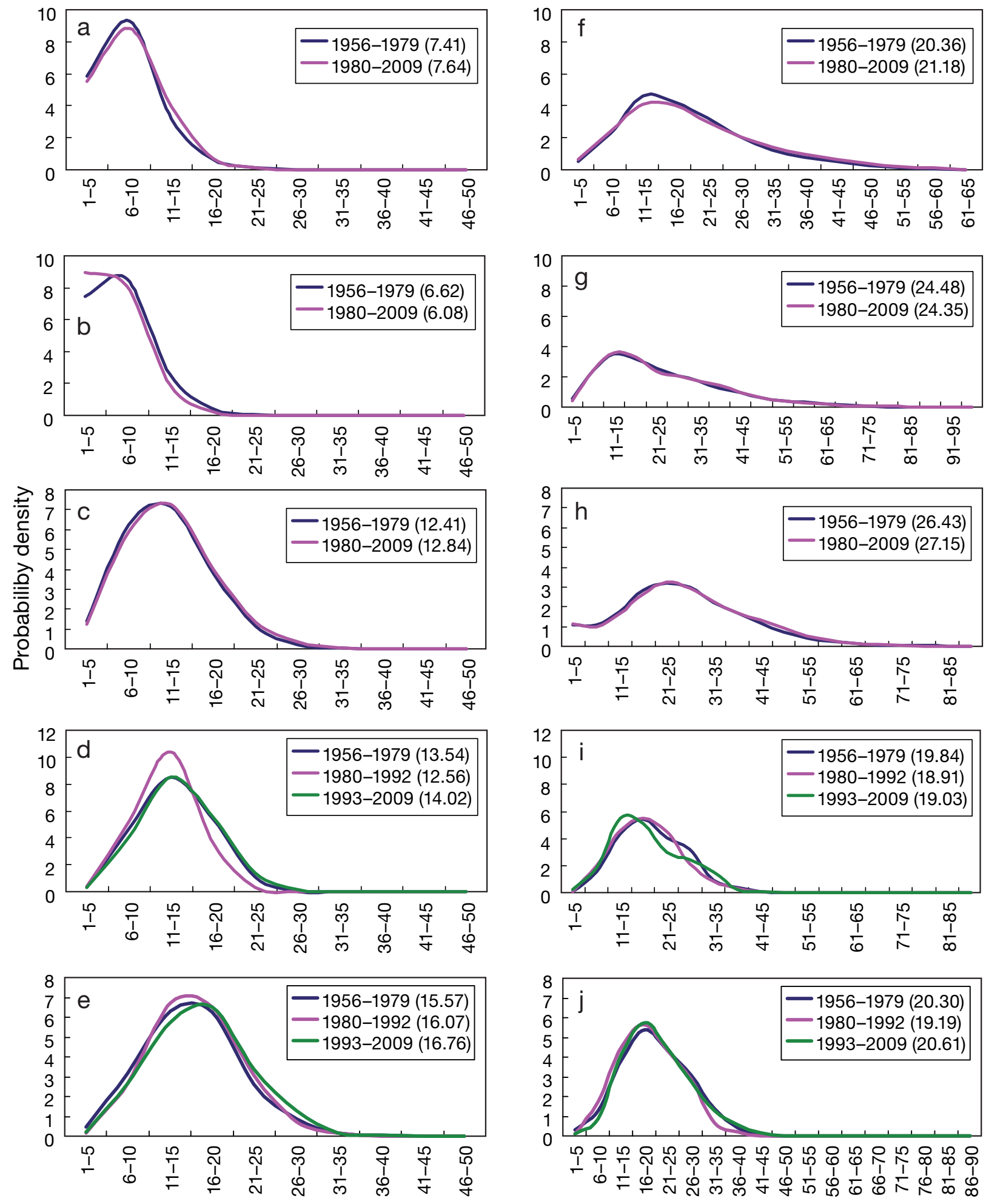

Frequency (d)

Fig. 11. Probability density curves for number of days with rainfall above the 95th percentile (R95p) in 5 sub-regions: (a,f) NE China $\left(115-135^{\circ} \mathrm{E}, 42-52^{\circ} \mathrm{N}\right),(\mathrm{b}, \mathrm{g})$ North China $\left(105-125^{\circ} \mathrm{E}, 35-42^{\circ} \mathrm{N}\right),(\mathrm{c}, \mathrm{h})$ Jianghuai Region $\left(105-122^{\circ} \mathrm{E}, 28-35^{\circ} \mathrm{N}\right),(\mathrm{d}, \mathrm{i})$ South China I $\left(105-110^{\circ} \mathrm{E}, 20-28^{\circ} \mathrm{N}\right)$, (e,j) South China II $\left(110-122^{\circ}\right.$ E, 20-28 $\left.{ }^{\circ} \mathrm{N}\right)$. (a-e) Observation, (f-j) BCC_CSM1.0. Numbers inside parentheses: spatio-temporal averaged values 
Table 2. Spatio-temporal averaged number of days with rainfall above the 95th percentile (R95p). OBS: observed, BCC: simulation by BCC_CSM1.0

\begin{tabular}{|lccccccc|}
\hline \multirow{2}{*}{ Region } & \multicolumn{2}{c}{$1956-1979$} & \multicolumn{2}{c}{$1980-2009$} & \multicolumn{2}{c|}{ 1980-1992 } & \multicolumn{2}{c}{ 1993-2009 } \\
& OBS & BCC & OBS & BCC & OBS & BCC & OBS \\
\hline NE China & 7.41 & 20.36 & 7.64 & 21.18 & - & - & - \\
North China & 6.62 & 24.48 & 6.08 & 24.35 & - & - & - \\
Jianghuai & 12.41 & 26.43 & 12.84 & 27.15 & - & - & - \\
South China I & 13.54 & 19.84 & 13.39 & 18.98 & 12.53 & 18.91 & 14.02 \\
South China II & 15.57 & 20.30 & 16.46 & 19.99 & 16.07 & 19.19 & 16.76 \\
\end{tabular}

\section{DISCUSSION}

Based on daily precipitation during 1956-2009 from 349 rain gauge stations in eastern China, the performance of the BCC_CSM1.0 in simulating the regional extreme precipitation change over eastern China (east of $105^{\circ} \mathrm{E}$ ) is evaluated. We also obtain similar results as previous research about the observation (e.g. Pan 2002, Zhai et al. 2005, Dong et al. 2011), such as the frequency and amount of extreme precipitation decreased in Northeast and North China, and increased in South China during the period of 1956 to 2009.

The 20th century simulation forced by observed greenhouse gases, aerosols, solar irradiance and volcanic aerosols shows that (1) BCC_CSM1.0 reproduces the basic feature of observed climatology of annual total and extreme precipitation over the 95th percentile, with spatial correlation of 0.77 for both of them, and (2) BCC_CSM1.0 captures the main change patterns of yearly accumulated extreme precipitations above the 95th percentile, although there are some model biases in the spatial extension and strength.

There are also some model biases: (1) the annual total and extreme precipitation south of Yangtze River are underestimated. (2) The frequency of heavy precipitation $\left(\geq 25.0 \mathrm{~mm} \mathrm{~d}^{-1}\right)$ over eastern China is underestimated, but the frequency of light rain $\left(0.1-10 \mathrm{~mm} \mathrm{~d}^{-1}\right)$ is overestimated. (3) The longterm trends of annual extreme precipitation amount and frequency in the recent $50 \mathrm{yr}$ are opposite to those from observations in North and South China. The model also has poor performance in simulating their interdecadal variations in North and South China.

The regional differences for extreme precipitation change is considerable and there are interdecadal variation signals for extreme heavy precipitation. Although some encouraging results for extreme precipitation simulation are obtained, the performance of BCC_CSM1.0 needs to be improved. IPCC AR4 models also have large biases in simulation of precipitation resulting from the East Asian summer monsoon (EASM) (Sun \& Ding 2008). It is therefore a common task for current climate system models to improve their performance in simulating the precipitation over East Asia.

A good simulation of the EASM is very important for precipitation simulation in East Asia. The probability of climate extremes is also strongly affected by atmospheric circulation and climate variability, such as Madden-Julian Oscillation, El Niño-Southern Oscillation, and Pacific interdecadal variability, in the global and/or regional scale (Jones et al. 2004, Curtis et al. 2007, Kenyon \& Hegerl 2010).

The climate system model working group in BCC are devoting themselves to improve the capability of BCC_CSM.

Acknowledgements. The authors thank the National Meteorological Information Center, China Meteorological Administration (CMA) for providing the daily station precipitation data, and they also thank the climate system model working group of National Climate Center, CMA, for their efforts in the development of the climate system model. This work is supported by the National Key Project of Scientific and Technical Supporting Programs of China (2007BAC29B02, 2007BAC29B03 and 2007BAC03A01) and National Basic Research Program of China (2010CB 951902), which are all from the Ministry of Science and Technology. This study is also supported by National Science Foundation of China (41175074). We also thank all reviewers and editors for their constructive suggestions. We thank Dr. Y. Cheng who made helpful suggestions on the content, syntax, and expressions.

\section{LITERATURE CITED}

Alexander LV, Zhang X, Peterson TC, Caesar J and others (2006) Global observed changes in daily climate extremes of temperature and precipitation. J Geophys Res 111:D05109, doi:10.1029/2005JD006290

Bonsal BR, Zhang XB, Vincent LA, Hogg WD (2001) Characteristics of daily and extreme temperature over Canada. J Clim 14:1959-1976 
Chelton DB, Schlax M, Witter D, Richman J and others (1990) GEOSAT altimeter observations of the surface circulation of the Southern Ocean. J Geophys Res 95: 17877-17903

Chen HS, Fu SD, Zhang XH (2009) Seasonal differences of variation characteristics of extreme precipitation events over China in the last 50 years. Transactions of Atmospheric Sciences 32:744-751 (in Chinese)

Chen XY (2008) Inter-annual change of East Asian Summer Monsoon and simulating analysis of BCC_CSM. MSc thesis, Nanjing University of Information Science \& Technology (in Chinese)

Curtis S, Salahuddin A, Adler RF, Huffman GJ, Gu G, Hong Y (2007) Precipitation extremes estimated by GPCP and TRMM: ENSO relationships. J Hydrometeor 8(4):679-689

Dickinson RE, Oleson KW, Bonan G, Hoffman F and others (2006) The Community Land Model and its climate statistics as a component of the Community Climate System Model. J Clim 19:2302-2324

> Ding YH, Wang ZY, Sun Y (2008) Inter-decadal variation of the summer precipitation in China and its association with decreasing Asian summer monsoon. Int J Climatol 28:1139-1161

Dong M, Wu TW, Wang ZZ, Zhang F (2009) Simulations of the tropical intra-seasonal oscillations by the AGCM of the Beijing Climate Center. Acta Meteorol Sin 67: 912-922 (in Chinese)

Dong Q, Chen X, Chen T (2011) Characteristics and changes of extreme precipitation in Yellow-Huaihe and YangtzeHuaihe River Basins, China. J Clim 24:3781-3795

Easterling DR, Evans JL, Groisman PY, Karl TR, Kunkel KE, Ambenje P (2000) Observed variability and trends in extreme climate events: a brief review. Bull Am Meteorol Soc 81:417-425

Gao XJ, Xu Y, Zhao ZC, Pal JS, Giorgi F (2006) Impacts of horizontal resolution and topography on the numerical simulation of East Asian precipitation. Chin J Atmos Sci 30:185-192 (in Chinese)

Gemmer M, Fischer T, Jiang T, Su BD, Liu LL (2011) Trends in precipitation extremes in the Zhujiang River Basin, South China. J Clim 24:750-761

$\mathrm{Hu}$ ZZ (1997) Interdecadal variability of summer climate over East Asia and its association with $500 \mathrm{hPa}$ height and global sea surface temperature. J Geophys Res 102: 19403-19412

Huang Y, Feng GL, Dong WJ (2011) Temporal changes in the patterns of extreme air temperature and precipitation in the various regions of China in recent 50 years. Acta Meteorol Sin 69:125-136 (in Chinese)

IPCC (2000) Emissions Scenarios. Nakicenovic N, Swart R (eds) Special Report of the Intergovernmental Panel on Climate Change (IPCC). Cambridge University Press, Cambridge

IPCC (2007) Climate change 2007: the physical science basis. Contribution of Working Group I to the Fourth Assessment Report of the Intergovernmental Panel on Climate Change. Solomon S, Qin D, Manning M, Chen Z, Marquis M, Averyt KB, Tignor M, Miller HL (eds). Cambridge University Press, Cambridge

Jiang ZH, Chen WL, Song J, Wang J (2009) Projection and evaluation of the precipitation extremes indices over China based on seven IPCC AR4 coupled climate models. Chin J Atmos Sci 33:109-120 (in Chinese)

> Jones C, Waliser DE, Lau KM, Stern W (2004) Global occurrences of extreme precipitation and the Madden-Julian
Oscillation: observations and predictability. J Clim 17: 4575-4589

Kalnay E, Kanamitsu M, Kistler R, Collins W and others (1996) The NCEP/NCAR 40-year reanalysis project. Bull Am Meteorol Soc 77:437-471

Karl TR, Easterling DR (1999) Climate extremes: selected review and future research directions. Clim Change 42: 309-325

Kendall MG (1948) Rank correlation methods. Hafner, New York, NY

Kendall MG (1975) Rank correlation measures. Charles Griffin, London

Kenyon J, Hegerl G (2010) Influence of modes of climate variability on global precipitation extremes. J Clim 23: 6248-6262

Kiehl JT, Gent PR (2004) The Community Climate System Model, version 2. J Clim 17:3666-3682

Kiktev D, Sexton DMH, Alexander L, Folland CK (2003) Comparison of modeled and observed trends in indices of daily climate extremes. J Clim 16:3560-3571

Li QX, Tang GL, Chen Y, Ren YY (2011) Summing-up report on monitoring and detection of precipitation over China during the last one hundred years. Department of Science \& Technology and Climate Change, China Meteorological Administration (in Chinese)

Mann HB (1945) Non-parametric tests against trend. Econometrica 13:245-259

Ning L, Qian YF (2009) Interdecadal change in extreme precipitation over South China and its mechanism. Adv Atmos Sci 26:109-118

North GR, Kim KY, Shen SSP, Hardin JW (1995) Detection of forced climatic signals. Part I: theory. J Clim 8:401-408

Pall P, Allen MR, Stone DA (2007) Testing the ClausiusClapeyron constraint on changes in extreme precipitation under $\mathrm{CO}_{2}$ warming. Clim Dyn 28:351-363

Pan XH (2002) The spatial and temporal characteristics of change of temperature and precipitation extremes over China during the second half of the 20th century. MSc thesis. Chinese Academy of Meteorological Sciences, Beijing (in Chinese)

Qian WH, Fu JL, Zhang WW, Xiang LN (2007) Changes in mean climate and extreme climate in China during the last 40 years. Adv Earth Sci 22:673-684 (in Chinese)

Sun Y, Ding YH (2008) Validation of IPCC AR4 climate models in simulating interdecadal change of East Asian summer monsoon. Acta Meteorol Sin 66:765-780

Sun Y, Solomon S, Dai AG, Portmann R (2006) How often does it rain? J Clim 19:916-934

Wang L, Zhou TJ, Wu TW and others (2009) Simulation of the leading mode of Asian-Australian monsoon interannual variability with Beijing Climate Center atmospheric general circulation model. Acta Meteorol Sin 67:973-982 (in Chinese)

Wang ZY, Ding YH, He JH, Yu J (2004) An updating analysis of the climate change in China in recent 50 years. Acta Meteorol Sin 62:228-236 (in Chinese)

Wei FY (1999) Technology of modern climate statistic diagnosis and prediction. China Meteorological Press, Beijing (in Chinese)

Weng HY, Sumi A, Takayabu YN, Minoto M, Li CY (2004) Interannual- interdecadal variation in large-scale atmospheric circulation and extremely wet and dry summers in China/Japan during 1951-2000. Part II: dominant timescales. J Meteorol Soc Jpn 82:789-804

Wu QZ (2002) A review of flood disasters in China in the 
20th century. J Catastrophol 17:62-69 (in Chinese)

$>$ Wu TW, Yu RC, Zhang F (2008) A modified dynamic framework for atmospheric spectral model and its application. J Atmos Sci 65:2235-2253

Wu TW, Yu RC, Zhang F, Wang Z, and others (2010) The Beijing Climate Center atmospheric general circulation model (BCC-AGCM2.0.1): description and its performance for the present-day climate. Clim Dyn 34:123-147

Xie P, Arkin PA (1997) Global precipitation: a 172 year monthly analysis based on gauge observations, satellite estimates, and numerical model outputs. Bull Am Meteorol Soc 78:2539-2558

Xu ZX, Chen YN, Li JY (2004) Impact of climate change on water resources in the Tarim River Basin. Water Resour Manage 18:439-458

Yan ZW, Yang C (2000) Geographic patterns of extreme climate changes in China during 1951-1997. Clim Environ Res 5:265-270 (in Chinese)

Yang JH, Jiang ZH, Wang PX, Chen YS (2008) Temporal and spatial characteristics of extreme precipitation events in China. Clim Environ Res 13:75-83 (in Chinese)

You QL, Kang SC, Aguilar E, Pepin N and others (2010) Changes in daily climate extremes in China and their connection to the large scale atmospheric circulation during 1961-2003. Clim Dyn 36:2399-2417

Zhai PM, Pan XH (2003) Change in extreme temperature

Submitted: February 28, 2011; Accepted: October 24, 2011 and precipitation over northern China during the second half of the 20th century. Acta Geogr Sin 58:1-10 (in Chinese)

Zhai PM, Ren FM, Zhang Q (1999a) Detection of trends in China's precipitation extremes. Acta Meteorol Sin 57: 208-216 (in Chinese)

Zhai PM, Sun AJ, Ren FM, Liu XN, Gao B, Zhang Q (1999b) Changes of climate extremes in China. Clim Change 42:203-218

> Zhai PM, Zhang XB, Wang H, Pan XH (2005) Trends in total precipitation and frequency of daily precipitation extremes over China. J Clim 18:1096-1108

Zhang L (2008) Evaluation of AOCGCMs for precipitation in East Asia. PhD thesis, Graduate University of the Chinese Academy of Sciences, Beijing (in Chinese)

Zhang L, Wu TW, Xin XG, Dong M, Wang ZZ (in press) Projected annual air temperature and precipitation over the Globe and China during the 21st century by BCC_ CSM1.0. Acta Meteorol Sin

Zhang X, Zwiers FW, Hegerl GC, Lambert FH and others (2007) Detection of human influence on twentiethcentury precipitation trends. Nature 448:461-465

> Zheng H, Zhang L, Liu C, Shao Q, Yoshihiro F (2007) Changes in stream flow regime headwater catchments of the Yellow River basin since the 1950s. Hydrol Process 21:886-893

Proofs received from author(s): December 4, 2011 